\title{
Human Security Index in Indonesia: Learning from Japan Human Security Index
}

\author{
Prepared by Prof. Dr. Dinil Pushpalal \\ Adj. Prof. Dr. Ismail Suardi Wekke \\ based on the book "SDG's and Japan," \\ written by Prof. Yukio Takasu
}

The United Nations declares "leaving no one behind" to be a principle of the Sustainable Development Goals (SDGs), but there is a growing recognition that it is inadequate to merely try to meet each target of the SDGs in order to accomplish this.

In this context, the Japan Human Security Indicator was developed to shed light on the realities of poverty, inequality, discrimination and exclusion in Japanese society. The Indicator was designed by a project team led by Yukio Takasu, Special Adviser on Human Security to the United Nations, and supported by volunteers from the NPO Human Security Forum, as well as experts and researchers in multiple fields. Besides, there is an index called Human Development Index (HDI). HDI is adopted by UNDP as a development indicator for ranking the countries. But HDI is not equal to HSI.

The HSI is composed of three indices, which are the core themes of human security: "life," "livelihood" and "dignity." In order to understand the geography of marginalization, these three indices are calculated from 88 indicators based on prefecture-level statistics issued mainly by public agencies.

In an attempt to gain the subjective perceptions of residents, the project team also conducted an online survey, asking participants questions on factors such as their anxiety, selffulfillment and isolation. 5,450 people responded and the data was used to form the prefectural ranking. According to the survey, despite the policies and institutions put in place by the central and the local governments, the team found that many people were still anxious about their old age, health, work, and lifestyle. Nearly a half of the respondents had no one who they could confide in about serious factors of distress, and a quarter answered that they could not find something worth living for.

It is understood that aggregate data about a single country is inadequate to understand the true state of a catastrophic event. Difficulty in living depended on diverse attributes of individuals such as region, generation, occupation, gender and disability. The originality of the indicator lay in the incorporation of subjective variables that explained specific human insecurities people experience in everyday life, and the examination of their anxieties and hopes.

The book "SDG's and Japan," has visualized HSI on a prefectural based country map and it proposes what improvements are needed for each prefecture. Among the all regions, Fukui prefecture showed the highest HSI, while Aomori is the lowest. 
Reference: Yoichi Mine, Ako Muto, 'Japan's Human Security' Indicator 2018 Symposium (https://www.jica.go.jp/jica-ri/news/topics/20181215_01.html) 


\section{LIFE INDEX: 23 INDICATORS}

\section{命指数 : 23 指標}

\section{A: Existence (11 indicators)}

$\mathrm{A}$ : 生命

\begin{tabular}{|c|c|c|}
\hline A1 & $\begin{array}{l}\text { 平均寿命 } \\
\text { Average life expectancy (Male) } \\
\text { Average life expectancy (Female) }\end{array}$ & \\
\hline A2 & $\begin{array}{l}\text { 人口増減率 } \\
\text { Population change rate }\end{array}$ & \\
\hline A3 & $\begin{array}{l}\text { 合計特殊生産率 } \\
\text { Total special production rate }\end{array}$ & \\
\hline A4 & $\begin{array}{l}\text { 生産年齢人口割合 } \quad(15-64 \text { 歳 }) \\
\text { Working-age population ratio }\end{array}$ & \\
\hline A5 & $\begin{array}{l}\text { 未婚率（50 歳時点） } \\
\text { Unmarried rate (at age 50) }\end{array}$ & 1 for low, 0 for high \\
\hline A6 & $\begin{array}{l}\text { 高齢単身世帯割合（65 歳以上） } \\
\text { Ratio of elderly single-person households (65 years old and over) }\end{array}$ & \\
\hline A7 & $\begin{array}{l}\text { ひとり親世帯の子供の割合 } \\
\text { Percentage of children in single-parent households }\end{array}$ & 1 for less, 0 for more \\
\hline A8 & $\begin{array}{l}\text { 自殺死亡者数（人口 } 10 \text { 万人あたり） } \\
\text { Suicide deaths (per 100,000 population) }\end{array}$ & \\
\hline A9 & $\begin{array}{l}\text { 自殺意識（念慮）率 } \\
\text { Suicide thought rate }\end{array}$ & \\
\hline A 10 & $\begin{array}{l}\text { 自然災害の死者・行方不明者数（人口 } 10 \text { 万人あたり） } \\
\text { Number of dead or missing due to natural disasters (per 100,000 } \\
\text { population) }\end{array}$ & \\
\hline A11 & $\begin{array}{l}\text { 交通事故死者数（人口 } 10 \text { 万人あたり） } \\
\text { Number of traffic fatalities (per 100,000 population) }\end{array}$ & \\
\hline
\end{tabular}

B: Health (12 indicators)

B: 健康保健

\begin{tabular}{|l|l|l|}
\hline B1 & $\begin{array}{l}\text { 健康寿命 } \\
\text { Healthy life expectancy (Male) } \\
\text { Healthy life expectancy (Female) }\end{array}$ & \\
\hline B2 & $\begin{array}{l}\text { 一般病院数 (人口 } 10 \text { 万人あたり) } \\
\text { Number of general hospitals (per 100,000 population) }\end{array}$ & \\
\hline
\end{tabular}




\begin{tabular}{|c|c|c|}
\hline B3 & $\begin{array}{l}\text { 一般病院病床数（人口 } 10 \text { 万人あたり） } \\
\text { General hospital beds (per 100,000 population) }\end{array}$ & \\
\hline B4 & $\begin{array}{l}\text { 医療施設に従事する医師数（人口 } 10 \text { 万人あたり） } \\
\text { Number of doctors engaged in medical facilities (per } \\
100,000 \text { population) }\end{array}$ & \\
\hline B5 & $\begin{array}{l}\text { 年間一人当たり医療費 } \\
\text { Annual medical expenses per person }\end{array}$ & \\
\hline B6 & $\begin{array}{l}\text { 健康診断受診率 } \\
\text { Health checkup consultation rate }\end{array}$ & 0 for low, 1 for high \\
\hline B7 & $\begin{array}{l}\text { 国民健康保険料滞納世帯割合 } \\
\text { Percentage of households with non-payment of National } \\
\text { Health Insurance premiums }\end{array}$ & \\
\hline B8 & $\begin{array}{l}\text { 障害者数 } \\
\text { Disabled people }\end{array}$ & $\begin{array}{l}\text { 指標に参入しない } \\
\text { This parameter is not included }\end{array}$ \\
\hline B9 & $\begin{array}{l}\text { 虫歯罹患率（12 歳児） } \\
\text { Caries prevalence (12-year-olds) }\end{array}$ & \\
\hline B10 & $\begin{array}{l}\text { 成人の喫煙率 } \\
\text { Adult smoking prevalence }\end{array}$ & \\
\hline B11 & $\begin{array}{l}\text { スポーツの年間行動者率（10 歳以上） } \\
\text { Annual rate of sports actors (10 years and older) }\end{array}$ & \\
\hline B12 & $\begin{array}{l}\text { 平均歩数（1 日当たり） } \\
\text { Average steps (per day) }\end{array}$ & 0 for less, 1 for more \\
\hline
\end{tabular}

\section{LIVELIHOOD INDEX: 42 INDICATORS}

\section{生活指数 42 指標}

C: Economic situation, labor work (10 indicators)

$\mathrm{C}$ : 経済状況、労働仕事 10 指標

\begin{tabular}{|l|l|l|}
\hline C1 & $\begin{array}{l}\text { 1 人当たり 県民所得 (年額) } \\
\text { Prefectural income per capita (annual) }\end{array}$ & \\
\hline C2 & $\begin{array}{l}1 \text { 世帯当たり 可処分所得 (月額) } \\
\text { Disposable income per household (monthly basis) }\end{array}$ & \\
\hline C3 & $\begin{array}{l}\text { ジニ係数 } \\
\text { Gini coefficient }\end{array}$ & \\
\hline C4 & $\begin{array}{l}\text { 失業率 } \\
\text { Unemployment rate }\end{array}$ & \\
\hline
\end{tabular}




\begin{tabular}{|l|l|l|}
\hline C5 & $\begin{array}{l}\text { 非正規雇用率 } \\
\text { Non-regular employment rate }\end{array}$ & \\
\hline C6 & $\begin{array}{l}\text { 女性の雇用率 } \\
\text { Female employment rate }\end{array}$ & \\
\hline C7 & $\begin{array}{l}\text { ひとり親世帯の正規雇用率 } \\
\text { Regular employment rate of single-parent households }\end{array}$ & \\
\hline C8 & $\begin{array}{l}\text { 障害者雇用数 } \\
\text { Employed persons with disabilities }\end{array}$ & \\
\hline C9 & $\begin{array}{l}\text { 高齢者有業率 (65 歳以上) } \\
\text { Elderly person working rate (65 years old and over) }\end{array}$ & \\
\hline C10 & $\begin{array}{l}\text { 財政力指数 } \\
\text { Financial capability index }\end{array}$ & \\
\hline
\end{tabular}

D: Education (11 indicators)

$\mathrm{D}$ : 教育 11 指標

\begin{tabular}{|c|c|c|}
\hline D1 & $\begin{array}{l}\text { 待機児童率 } \\
\text { Waiting child rate }\end{array}$ & \\
\hline D2 & $\begin{array}{l}\text { 小学校児童数（教員 } 1 \text { 人あたり） } \\
\text { Elementary school children (per teacher) }\end{array}$ & \\
\hline D3 & $\begin{array}{l}\text { 中学校生徒数（教員 } 1 \text { 人あたり） } \\
\text { Junior high school students (per teacher) }\end{array}$ & \\
\hline D4 & $\begin{array}{l}\text { 就学援助受給者割合 } \\
\text { Percentage of recipients of enrollment assistance }\end{array}$ & \\
\hline D5 & $\begin{array}{l}\text { 高校中退率 } \\
\text { High school dropout rate }\end{array}$ & \\
\hline D6 & $\begin{array}{l}\text { 大学進学率 } \\
\text { University enrollment rate }\end{array}$ & \\
\hline D7 & $\begin{array}{l}\text { 不登校率 } \\
\text { school absenteeism rate }\end{array}$ & \\
\hline D8 & $\begin{array}{l}\text { 子どもの学力の達成度 } \\
\text { Achievement of children's academic ability }\end{array}$ & \\
\hline D9 & $\begin{array}{l}\text { 子どもの運動能力 } \\
\text { Children's athletic ability }\end{array}$ & 0 for low, 1 for high \\
\hline D10 & $\begin{array}{l}\text { 社会教育学級講座数 } \\
\text { Number of social Education Classes }\end{array}$ & 0 for less, 1 for more \\
\hline D11 & $\begin{array}{l}\text { 夜間中学・定時制高校数 } \\
\text { Number of night junior high school and part-time high school }\end{array}$ & \\
\hline
\end{tabular}




\section{E: Welfare (11 indicators)}

$\mathrm{E}$ : 福祉 11 指標

\begin{tabular}{|c|c|c|}
\hline E1 & $\begin{array}{l}\text { 児童扶養手当受給率（対全世帯） } \\
\text { Child Dependent Allowance Recipients Rate（to All } \\
\text { Households) }\end{array}$ & \\
\hline E2 & $\begin{array}{l}\text { 児童養護施設数（人口 } 10 \text { 万人あたり） } \\
\text { Number of orphanages (per 100,000 population) }\end{array}$ & \\
\hline E3 & $\begin{array}{l}\text { 児童相談件数（人口千人あたり） } \\
\text { Number of child consultations (per 1,000 people) }\end{array}$ & \\
\hline E4 & $\begin{array}{l}\text { 生活保護受給率 } \\
\text { Rate of recipients receiving welfare benefits }\end{array}$ & \\
\hline E5 & $\begin{array}{l}\text { 生活困笨者自立支援の相談件率（人口 } 10 \text { 万人あた } \\
\text { り、月間） } \\
\text { Rate of consultation from necessitous person to become } \\
\text { self-reliance (per 100,000 population, monthly) }\end{array}$ & \\
\hline E6 & $\begin{array}{l}\text { 高齢者用施設数（65 歳以上人口 } 10 \text { 万人あたり） } \\
\text { Number of facilities for the elderly people (per 100,000 } \\
\text { people aged } 65 \text { and over) }\end{array}$ & \\
\hline E7 & $\begin{array}{l}\text { 高齢者用施設在所者数（65 歳以上人口千人あたり） } \\
\text { Number of residential facilities for the elderly people (per } \\
1,000 \text { people over the age of } 65 \text { ) }\end{array}$ & $\begin{array}{l}\text { 指標に参入しない } \\
\text { This parameter is not included }\end{array}$ \\
\hline E8 & $\begin{array}{l}\text { 特養施設待機人数 } \\
\text { Number of people waiting for special facilities }\end{array}$ & \\
\hline E9 & $\begin{array}{l}\text { 介護職員数 } \\
\text { Number of caregiving staff }\end{array}$ & \\
\hline E10 & $\begin{array}{l}\text { 民生委員数（人口 } 10 \text { 万人あたり） } \\
\text { Number of commissioned welfare volunteers (per 100,000 } \\
\text { population) }\end{array}$ & \\
\hline E11 & $\begin{array}{l}\text { 生活保護のケースワーカーの担当世帯数 } \\
\text { Number of households in charge of welfare caseworkers }\end{array}$ & \\
\hline
\end{tabular}


F: Lifestyle, environment, safety (10 indicators)

$\mathrm{F}$ : 生活習慣、環境、安全 10 指標

\begin{tabular}{|c|c|c|}
\hline F1 & $\begin{array}{l}\text { インターネット利用率 } \\
\text { Internet usage rate }\end{array}$ & \\
\hline $\mathrm{F} 2$ & $\begin{array}{l}\text { ユネスコスクール数 } \\
\text { Number of UNESCO schools }\end{array}$ & $\begin{array}{l}\text { 指標に参入しない } \\
\text { This parameter is not included }\end{array}$ \\
\hline F3 & $\begin{array}{l}\text { バリアフリー率（鉄道駅） } \\
\text { Barrier-free rate (train stations) }\end{array}$ & \\
\hline $\mathrm{F} 4$ & $\begin{array}{l}1 \text { 人当たり温室効果ガス排出量（年間） } \\
\text { Greenhouse gas emissions per person (annual) }\end{array}$ & 1 for less, 0 for more \\
\hline F5 & $\begin{array}{l}1 \text { 住宅当たりの住居延べ面積 } \\
\text { Residential area per house }\end{array}$ & \\
\hline F6 & $\begin{array}{l}\text { ごみのリサイクル率 } \\
\text { Garbage recycling rate }\end{array}$ & \\
\hline F7 & $\begin{array}{l}\text { 污水処理率 } \\
\text { Sewage treatment rate }\end{array}$ & \\
\hline F8 & $\begin{array}{l}\text { 公共施設の耐震化率 } \\
\text { Seismic retrofit rate of public facilities }\end{array}$ & \\
\hline F9 & $\begin{array}{l}\text { 上水道の基幹管路の耐震化率 } \\
\text { Seismic retrofit rate of main water supply pipeline }\end{array}$ & \\
\hline F10 & $\begin{array}{l}\text { 刑法犯知件数（人口 } 10 \text { 万人あたり） } \\
\text { Criminal offenses (per 100,000 population) }\end{array}$ & \\
\hline
\end{tabular}

\section{DIGNITY INDEX: 26 INDICATORS}

尊厳指数 26 指標

G: Children and women (7 indicators)

G：子供と女性 7 指標

\begin{tabular}{|l|l|l|}
\hline G1 & $\begin{array}{l}\text { いじめ件数（児童・生徒千人あたり） } \\
\text { Number of bullying cases (per 1,000 children / students) }\end{array}$ & \\
\hline G2 & $\begin{array}{l}\text { 子どもの一時保護所受入れ平均在所日数 } \\
\text { Average number of days of children in temporary shelters }\end{array}$ & \\
\hline G3 & $\begin{array}{l}\text { 里親委託率 } \\
\text { Foster care trust rate }\end{array}$ & \\
\hline G4 & $\begin{array}{l}\text { 子どもの自殺率 (20 歳未満) } \\
\text { Child suicide rate (under 20 years) }\end{array}$ & \\
\hline
\end{tabular}




\begin{tabular}{|l|l|l|}
\hline G5 & $\begin{array}{l}\text { DV 被害者の一時保護件数（人口 } 10 \text { 万人あたり） } \\
\text { Rate of temporary protection of DV victims (per 100,000 } \\
\text { population) }\end{array}$ & \\
\hline G6 & $\begin{array}{l}\text { 男性の家事・育児の分担時間数 } \\
\text { Number of men's housework and childcare hours }\end{array}$ & 0 for less, 1 for more \\
\hline G7 & $\begin{array}{l}\text { 男女の賃金差 } \\
\text { Gender based salary gap }\end{array}$ & \\
\hline
\end{tabular}

$\mathrm{H}:$ Trust in the public (6 indicators)

$\mathrm{H}$ : 公への信頼 6 指標

\begin{tabular}{|l|l|l|}
\hline H1 & $\begin{array}{l}\text { 国政選挙投票率 } \\
\text { National election turnout }\end{array}$ & \\
\hline H2 & $\begin{array}{l}\text { 女性の地方議員割合 } \\
\text { Percentage of female members of parliament }\end{array}$ & \\
\hline H3 & $\begin{array}{l}\text { 情報公開度 } \\
\text { Degree of information disclose }\end{array}$ & $\begin{array}{l}\text { Number of inquiries to Japan Legal Support Center } \\
\text { (per 10,000 people) }\end{array}$ \\
\hline H4 & $\begin{array}{l}\text { 弁護士人数 (人口 } 1 \text { 万人あたり) } \\
\text { Number of lawyers (per 10,000 people) }\end{array}$ & \\
\hline H6 & $\begin{array}{l}\text { 人権侵犯件数 (人口 1 万人あたり) } \\
\text { Number of human rights violations (per 10,000 people) }\end{array}$ & \\
\hline
\end{tabular}

$\mathrm{J}$ : Community, solidarity, internationality (11 indicators)

$\mathrm{J}$ : 地域社会、連帯感、国際性 11 指標

\begin{tabular}{|c|c|}
\hline $\mathrm{J} 1$ & $\begin{array}{l}\text { 国指定文化財の件数（人口 } 1 \text { 万人あたり） } \\
\text { Number of nationally designated cultural properties (per } \\
10,000 \text { people) }\end{array}$ \\
\hline $\mathrm{J} 2$ & $\begin{array}{l}\text { 文化施設及び公民館数（人口 } 1 \text { 万人あたり） } \\
\text { Number of cultural facilities and community centers (per } \\
10,000 \text { people) }\end{array}$ \\
\hline $\mathrm{J} 3$ & $\begin{array}{l}\text { 地縁団体数（人口 } 1 \text { 万人あたり） } \\
\text { Number of territorial groups (per 10,000 people) }\end{array}$ \\
\hline $\mathrm{J} 4$ & $\begin{array}{l}\text { ボランティア活動の年間行動者率 } \\
\text { Rate of people engage in volunteer activities (annual) }\end{array}$ \\
\hline
\end{tabular}




\begin{tabular}{|c|c|c|}
\hline J5 & $\begin{array}{l}\text { ふるさと納税者数（人口 } 1 \text { 万人あたり） } \\
\text { Number of people engage in “benefit-your-locality tax } \\
\text { scheme” (per 10,000 people) }\end{array}$ & \\
\hline $\mathrm{J} 6$ & $\begin{array}{l}\text { 主要な国際支援団体への寄付人数（人口 } 10 \text { 万人あた } \\
\text { り) } \\
\text { Number of people donate to major international } \\
\text { organizations (per 100,000 population) }\end{array}$ & \\
\hline $\mathrm{J} 7$ & $\begin{array}{l}\text { NPO 団体数（人口 } 1 \text { 万人あたり） } \\
\text { Number of NPO (per 10,000 people) }\end{array}$ & \\
\hline $\mathrm{J} 8$ & $\begin{array}{l}\text { 外国人居住者数の増加率 } \\
\text { Growth rate of foreign residents }\end{array}$ & 0 for low, 1 for high \\
\hline J9 & $\begin{array}{l}\text { 留学生数（人口 } 1 \text { 万人あたり） } \\
\text { Number of international students (per 10,000 people) }\end{array}$ & \\
\hline $\mathrm{J} 10$ & $\begin{array}{l}\text { 技能実習生数 } \\
\text { Number of technical interns }\end{array}$ & 0 for low, 1 for high \\
\hline J11 & $\begin{array}{l}\text { 自分の住む地域に外国人が増えることを歓迎する割 } \\
\text { 合 } \\
\text { Percentage of people those who welcome the increase of } \\
\text { foreigners in their area }\end{array}$ & \\
\hline
\end{tabular}

L: Level of satisfaction (2 indicators)

$\mathrm{L}$ : 満足度 2 指標

\begin{tabular}{|l|l|l|}
\hline L1 & $\begin{array}{l}\text { 自分の人生に満足していない人の割合 } \\
\text { Percentage of people those who are not satisfied with their } \\
\text { life }\end{array}$ & \\
\hline L2 & $\begin{array}{l}\text { 自分の人生が将来今より良くなると思わない人の割 } \\
\text { 合 } \\
\text { Percentage of people those who do not think their life will } \\
\text { be better in the future }\end{array}$ & \\
\hline
\end{tabular}

